\title{
URBANIZAÇÃO SUSTENTÁVEL: MÉTRICAS ESPACIAIS E TIPOLOGIAS DE CRESCIMENTO
}

\author{
Isabel Cristina Nunes de Sousa \\ Doutoranda em Geografia, Bolsista do CNPq-Brasil \\ Universidade Estadual Paulista (Unesp), Instituto de Geociências e \\ Ciências Exatas, Rio Claro, SP, Brasil \\ icn.sousa@unesp.br \\ Ivan Damasco Menzori \\ Doutor em Engenharia Urbana \\ Universidade Federal de São Carlos - PPGEU/UFSCar, São Carlos, SP, Brasil \\ menzori@ufscar.br \\ Roberto Braga \\ Doutor em Geografia Humana, livre-docente em Planejamento Urbano e Regional \\ Universidade Estadual Paulista (Unesp), Instituto de Geociências e \\ Ciências Exatas, Rio Claro, SP, Brasil \\ roberto.braga@unesp.br
}

\begin{abstract}
RESUMO
Cidades compactas e com maiores densidades demográficas, combinadas à adequada provisão de espaços livres públicos, podem representar padrões ambientalmente mais sustentáveis de ocupação humana, em comparação às formas dispersas. Nesta pesquisa foi avaliado o crescimento urbano em uma cidade média não metropolitana do interior paulista (São Carlos) no período de vigência de seu primeiro Plano Diretor (aprovado em 2005 e revisado em 2016), por meio da aplicação de métricas espaciais para mensuração da forma urbana, e classificação das tipologias de crescimento urbano. A partir disso, discutiu-se as relações entre a forma e a produção do espaço urbano. Durante a vigência do Plano Diretor do município em questão (2005 a 2016) houve adensamento, mas também dispersão e aumento da descontinuidade da mancha urbana, com diminuição da compacidade e expansão dos limites periurbanos.
\end{abstract}

Palavras-chave: Sustentabilidade urbana. Cidade compacta. Crescimento urbano. Expansão urbana. Plano Diretor.

\section{SUSTAINABLE URBANIZATION: SPATIAL METRIC AND GROWTH TYPOLOGIES}

\begin{abstract}
Compact cities with higher demographic densities, combined with adequate provision of public open spaces, can represent more environmentally sustainable patterns of human settlement, compared to dispersed forms. In this paper, we analyze the urban growth in a medium-sized, non-metropolitan city in the State of São Paulo (São Carlos city), during the regency of its first Master Plan (approved in 2005 and reviewed in 2016), through the application of spatial metrics of urban form, and classification of growth typologies. Based on that, we discuss the relations between form and development in the urbanized space. During the Master Plan's regency in the city in question (2005 to 2016) there was densification, but also dispersion and increased discontinuity in the urban area, with a decrease in compactness and expansion of peri-urban limits.
\end{abstract}

Keywords: Urban sustainability. Compact city. Urban growth. Urban expansion. Master Plan.

\section{INTRODUÇÃO}

Em diversos contextos não metropolitanos, a urbanização brasileira tem se caracterizado pela formação de um padrão disperso de ocupação urbana (SANTORO; COBRA; BONDUKI, 2010), marcado por baixas densidades e dependente dos transportes motorizados. Esse padrão ocasiona diversas implicações socioambientais e econômicas, sendo identificado pelo aumento da extensão territorial das cidades, muitas vezes de modo descontínuo à mancha urbana e superior ao incremento demográfico, ilustrando um "[...]

\begin{tabular}{|c|c|c|}
\hline & Caminhos de Geografia Uberlândia $\quad$ v. 22, n. 84 \\
\hline
\end{tabular}


descompasso entre o crescimento populacional e a expansão física do espaço urbano" (OJIMA, 2008, p. 48).

Os impactos ambientais decorrentes da expansão territorial urbana são diversos, sendo os mais evidentes referentes à fragmentação da paisagem e perda de habitats naturais. Nessa perspectiva, alterações no uso do solo que incluem a conversão de ecossistemas naturais em áreas agrícolas ou urbanas, exercem efeitos significativos sobre a extinção de espécies e a consequente redução da biodiversidade (ROCKSTRÖM et al., 2009), interferindo na provisão de serviços ecossistêmicos como polinização (FOLEY et al., 2005). Ademais, existem evidências que relacionam as alterações no uso do solo com as mudanças climáticas globais (SETO e SHEPHERD, 2009), e com o surgimento de doenças infecciosas causadas por patógenos zoonóticos - que têm uma fonte animal não humana (JONES et al., 2008). Além disso, cabe mencionar a existência de impactos indiretos da expansão urbana, que ultrapassam os diretos e estão associados ao deslocamento e conversão de áreas agrícolas (VAN VLIET, 2019).

A expansão dos ambientes urbanos e o consequente aumento das áreas impermeabilizadas também contribui para alterações nas temperaturas locais e formação de ilhas de calor urbanas, ocasionando em mudança nos padrões de precipitações, circulação do ar e dispersão de poluentes (GRIMM et al., 2008), além de aumentar o escoamento superficial, que contribui para os episódios de enchentes, inundações e alagamentos ${ }^{1}$ nas cidades. Em síntese, a expansão urbana relaciona-se a alterações locais e globais nos ciclos biogeoquímicos, no clima, nos sistemas hídricos e na biodiversidade (lbid.), de tal maneira que "o crescimento e a expansão urbana trazem, em seu próprio processo constitutivo, riscos e perigos que se expressam pela falta de ajuste e aderência da produção do espaço urbano aos sistemas naturais [...]" (MARANDOLA JR. et al., 2013, p. 36).

Uma urbanização dispersa também amplia as distâncias entre residências e empregos, desestimulando os modos ativos de transporte (caminhada e bicicleta) e gerando um incremento na dependência dos meios de transporte motorizados para os deslocamentos diários (DEUS e SANCHES, 2009), o que pode acarretar na elevação dos congestionamentos, com consequente aumento da poluição sonora e diminuição da qualidade do ar. Simultaneamente, entretanto, não se pode ignorar os efeitos deletérios de uma urbanização mais compacta, a exemplo da intensificação das ilhas de calor urbanas em âmbito local, que tem sido associada a tais formas urbanas (ZHOU; RYBSKI; KROPP, 2017). Ainda assim, do ponto de vista global, a compacidade urbana é considerada preferencial por seu potencial de reduzir o consumo energético e as emissões de $\mathrm{CO}_{2}$ (MARTILLI, 2014). Uma abordagem holística, no entanto, demanda refletir sobre os tipos de desenvolvimento compacto a serem promovidos, de maneira a não menosprezar, por exemplo, o papel desempenhado pela presença de vegetação nos sistemas de espaços livres das cidades (ARTMANN; INOSTROZA; FAN, 2019), especialmente quando se considera o desconforto e o estresse térmico ocasionado por cidades muito compactas e desprovidas de vegetação (MARTILLI, 2014).

Logo, "[...] a utilização do território não tem apenas implicações sociais e econômicas, mas também importantes efeitos sobre os sistemas naturais" (HIDALGO; VOLKER; RAMíREZ, 2014, p. 15). Por conseguinte, "combater os problemas ambientais urbanos significa, assim, em primeiro lugar, combater o caráter exclusivamente mercantil da expansão das cidades e suas implicações sociais" (SOUZA, 2015, p. 177).

Não obstante existam trabalhos que avancem na compreensão dos processos de produção do espaço urbano $^{2}$ em cidades médias (BARCELLA e MELAZZO, 2020), este estudo abrange a relação desse processo com a configuração espacial (características espaciais do ambiente urbano). Assim sendo, nesta pesquisa avaliou-se como se deu a expansão territorial urbana em uma cidade média não metropolitana do interior paulista (São Carlos), no período de vigência de seu primeiro Plano Diretor (aprovado em 2005 e revisado em 2016). Para isso, foram averiguadas as transformações na forma urbana, sendo identificado o tipo de crescimento urbano predominante no período (2005-2016).

O fato de o Plano Diretor ser o instrumento básico da política de desenvolvimento e expansão urbana justifica sua escolha como delimitação temporal para análise, pois o mesmo deve expressar todo o entendimento do município acerca de seu território, devendo definir para onde e como a cidade se expandirá fisicamente (BRASIL, 2001). Nesse sentido, políticas de uso e ocupação do solo, como o zoneamento e os planos diretores, influenciam na configuração espacial das cidades (GRIMM et al., 2008).

${ }^{1}$ Os três fenômenos se diferenciam da seguinte forma: "enchente é a elevação temporária do nível d'água no canal de drenagem [...] sem extravasar; inundação é o transbordamento ou extravasamento das águas de um curso d'água [...] e alagamento é o acúmulo momentâneo de água em determinados locais [...]" (COELHO, 2016, p. 45-46, grifos da autora).

2 "A 'produção' de espaço urbano se dá, em geral, pela incorporação à cidade de glebas que antes tinham uso agrícola" (SINGER, 1980 , p. 79 , grifo do autor).

Caminhos de Geografia

Uberlândia - MG $\quad$ v. 22, n. 84

dez/2021

p. $36-55$

Página 37 


\section{SUSTENTABILIDADE URBANA}

O termo 'sustentabilidade' é amplamente utilizado para se referir à sustentabilidade ecológica, não obstante, a ideia de que o compromisso de sustentar o capital natural/ambiental deve ser combinado com o atendimento das necessidades humanas tem sido cada vez mais aceita. Nesse sentido, o componente 'sustentável' do desenvolvimento pode ser entendido como "[...] a garantia de atendimento às necessidades humanas sem o uso de recursos e a geração de resíduos em níveis que ameacem a sustentabilidade ecológica local, regional e global" (MITLIN e SATTERTHWAITE, 2002, p. 33, tradução própria).

A respeito da sustentabilidade urbana, o crescimento da população nos padrões atuais é considerado crítico para o meio ambiente (MARTINE, 2007), de tal maneira que a discussão recai sobre a questão da densidade populacional, pautando-se no pressuposto de que, quanto maior a concentração de pessoas no espaço, menor o consumo de recursos naturais e maior o aproveitamento de energia (GÜNERALP et al., 2017) e das infraestruturas existentes (SILVA; RAIA JR; FERRAZ, 2004).

Devido à finitude de muitos recursos naturais, e à limitada capacidade de suporte do ambiente natural em absorver ou decompor os resíduos, a relevância dos padrões de produção e consumo se sobrelevam na esfera urbana. Conforme Martine (2007, p. 186), as cidades "têm impactos ambientais sérios porque concentram tanto a população quanto a atividade econômica e a riqueza, mas tais efeitos estão associados a um determinado padrão de civilização e poderiam ser abrandados".

Por concentrarem uma quantidade maior de pessoas, cidades compactas e com densidades mais elevadas, combinadas a uma adequada provisão de espaços públicos livres (como áreas verdes), representariam padrões ambientalmente mais sustentáveis de ocupação humana, em comparação a formas dispersas - 0 que restringiria a necessidade de expansão das fronteiras urbanas que, frequentemente, incorre na perda de terras férteis e de elevada relevância ambiental. No entanto, embora o adensamento seja um aspecto favorável à sustentabilidade urbana, é necessária uma visão crítica a respeito dos interesses que direcionam esse processo, especialmente quando são consideradas as implicações da transferência de princípios de planejamento urbano oriundos de experiências e contextos político-econômicos distintos (YUNDA; SLETTO, 2020), como é o caso, por exemplo, da noção de cidade compacta, largamente inspirada em um paradigma eurocêntrico, no qual a maioria da literatura científica abarca contextos urbanos referentes ao Norte Global (ZAPATA-CAMPOS et al., 2021), sendo considerado até "um conceito baseado em pressupostos ou em um imaginário urbano não isento de uma certa nostalgia da tradicional cidade mediterrânea" (NAVARRO VERA; ORTUÑO PADILLA, 2011, p. 38, tradução própria).

Ainda assim, considerando o previsto incremento da população urbana nos próximos 30 anos, em que se espera alcançar 9,7 bilhões de pessoas em 2050 (UN, 2019), é presumível que ocorra um aumento na área urbanizada. No entanto, é questionável se esse crescimento será sustentável, em virtude dos atuais moldes em que o desenvolvimento das cidades vem ocorrendo, com decréscimo na densidade residencial devido à taxa de expansão urbana substancialmente superior ao crescimento populacional (ANGEL et al., 2016; LIU et al., 2020).

Nessa prerrogativa, a urbanização sustentável incorpora, dentre outros fatores, uma forma urbana mais compacta, com densidades mais elevadas do que os parâmetros atualmente existentes na maioria das cidades, onde se constata um crescimento urbano espraiado, com "aumento da área urbanizada maior que o aumento da população, indicando um uso não eficiente da infraestrutura urbana" (PEREIRA et al., 2019, p. 18). No entanto, visto que um modelo menos disperso de urbanização não se limita à elevação das densidades, é preciso reconhecer a singularidade de cada contexto e a inexistência de uma receita universal de cidade compacta (ZAPATA-CAMPOS et al., 2021).

Sob tal perspectiva, comparado à Europa, Estados Unidos e Austrália, por exemplo, padrões mais densos de ocupação já são uma realidade no Brasil - em grande medida devido aos maiores níveis de "compactação nos assentamentos informais" (ABRAMO, 2007, p. 37). Contudo, a propensão à diminuição das densidades urbanas é um fenômeno global (SETO et al., 2011), sendo registrados declínios em diversos países latinoamericanos (ANGEL et al., 2016).

\section{TENDÊNCIAS DA URBANIZAÇÃO DE SÃO CARLOS-SP}

A pesquisa teve como recorte territorial o município de São Carlos (Figura 1), localizado na região central do estado de São Paulo (mesorregião de Araraquara), a cerca de 230 quilômetros da capital paulista. Tratase de um município com elevado grau de urbanização (96\%), 1.137,30 km² de área (cerca de $6 \%$ do território urbanizado), população estimada em 256.915 habitantes para 2021, e densidade demográfica de 195,15 $\mathrm{hab} . / \mathrm{km}^{2}$ (SÃO CARLOS, 2010; IBGE, 2021; SEADE, 2019).

\begin{tabular}{llllll}
\hline Caminhos de Geografia & Uberlândia - MG & v. 22, n. 84 & dez/2021 & p. 36-55 & Página 38
\end{tabular}


Figura 1 - São Carlos (SP): Localização do município, 2016

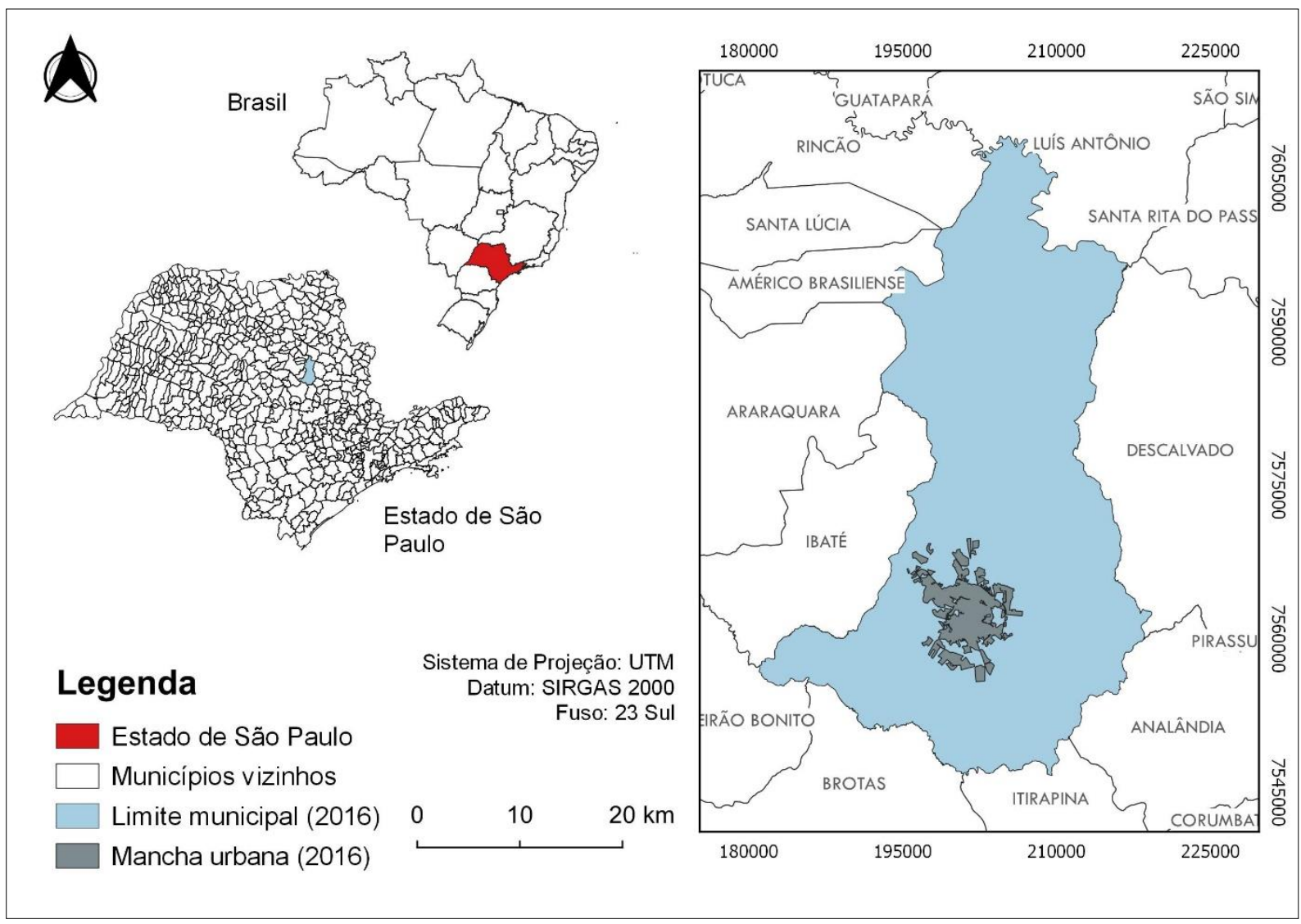

Fonte: Elaboração própria (2020), com base em informações do Instituto Brasileiro de Geografia e Estatística (IBGE, 2015) e de dados de Faustino (2017).

São Carlos-SP teve um desenvolvimento historicamente atrelado à ampliação da fronteira agrícola de café no final do século XIX. Na década de 1970, com a tendência de urbanização articulada ao êxodo rural, o município destacou-se por seu crescimento populacional superior ao de sua Região de Governo e ao Estado de São Paulo, sendo um dos polos de forte atração migratória e o município que mais cresceu em termos populacionais, quando comparado a outros municípios vizinhos de mesmo porte (SÃO CARLOS, 2010).

Até 1940 a cidade "se mostrava compacta, com uma grande facilidade de deslocamentos gerada por distâncias curtas" (PERES, 2012, p. 265). Posteriormente, contudo, a ocupação urbana tornou-se "bastante rarefeita, com uma dispersão significativa da população no perímetro urbano", indo em direção ao extremo sul por populações de baixa renda, visto a atratividade ocasionada pela presença da ferrovia, e ao noroeste do centro urbano por populações de maior renda (SÃO CARLOS, 2010, p. 26-27). Essa contrastante ocupação físico-territorial refletiu-se, também, na provisão de serviços e equipamentos públicos, com precariedade e insuficiência na região sul (SÃO CARLOS, 2010).

\section{AVALIAÇÃO DA SUSTENTABILIDADE DA FORMA URBANA}

A avaliação das transformações na forma urbana baseou-se em uma análise comparativa dos resultados da aplicação de métricas espaciais para os cenários de 2005 e 2016. Isso porque, considerando que a forma urbana descreve um status estático de uso e ocupação do solo (XU et al., 2020), a aplicação em dois momentos visou quantificar o processo de urbanização no período, sob uma perspectiva mais dinâmica ${ }^{3}$.

\footnotetext{
${ }^{3}$ Conforme Krafta e Silva (2020, p. 2), os padrões de formas urbanas podem ser diferenciados pelos "meios de descrição estáticos (descrição de estado da forma urbana) e dinâmicos (descrição da mudança de estado da forma urbana)".

$\begin{array}{llllll}\text { Caminhos de Geografia } & \text { Uberlândia - MG } & \text { v. 22, n. } 84 & \text { dez/2021 } & \text { p. 36-55 } & \text { Página } 39\end{array}$
}


As mencionadas métricas são calculadas com base em seis equações (BRAGA, 2016) que, por terem sido elaboradas a partir do conceito de densidade sustentável e das dimensões da forma urbana na perspectiva da sustentabilidade (ocupação, densidade, dispersão, compacidade e descontinuidade), podem ser consideradas indicadores viáveis para avaliação da sustentabilidade urbana (Ibid.).

Ainda assim, algumas ressalvas metodológicas precisam ser apontadas, a exemplo das variáveis "área" e "perímetro" da mancha urbana, influenciadas diretamente por feições naturais e artificiais que contribuem para o fracionamento do território, tais como cursos d'água e Áreas de Preservação Permanente (APP), encostas, faixas de domínio rodoviárias e ferroviárias, dentre outras, que não necessariamente representam ineficiência, mas sim condicionantes do meio físico. A despeito de sua importância, a resolução de tal limitação ultrapassa as pretensões deste trabalho. Por conseguinte, as áreas verdes foram consideradas como virtualmente inexistentes neste estudo, não sendo, portanto, representadas nos mapas nem desconsideradas nos cálculos das métricas espaciais. Isso porque as mesmas já cumprem uma função social mesmo desocupadas, simplesmente por existirem.

A equação 1 refere-se à Taxa de Ocupação (TO), que corresponde ao percentual da zona urbana (área delimitada pelo perímetro urbano) ocupado pelas manchas urbanas. Conforme Braga (2016, p. 38-39), "quanto menor a taxa de ocupação, menor a sustentabilidade, pois o excesso de área urbana periférica não ocupada estimula a fragmentação do tecido urbano e induz a [formação de] novos vazios urbanos".

$\sum_{i=1}^{n}\left[\frac{s i}{s t}\right]$

Em que:
si - área da mancha urbana i
st - área delimitada pelo perímetro urbano

A equação 2 refere-se à Densidade urbana da área ocupada (DU), calculada pela divisão da população urbana total pela área total das manchas urbanas.

$\mathrm{DU}=\mathrm{p} / \mathrm{s}$

\section{Em que:}

p - população urbana

$\mathrm{s}$ - área total das manchas urbanas dentro do perímetro urbano

A equação 3 refere-se à Densidade urbana do perímetro (DUP), calculada pela divisão da população urbana total pela área da zona urbana (área delimitada pelo perímetro urbano) como um todo.

DUP $=p / s p$

Em que:

p - população urbana

$\mathrm{sp}$ - área do perímetro urbano

A equação 4 refere-se ao Índice de Dispersão (IDisp), empregado para avaliar a proximidade das manchas urbanas secundárias da mancha urbana principal. De acordo com Braga (2016, p. 39), "quanto mais próximas [as manchas urbanas] estiverem entre si, mais sustentável é a forma urbana, pois distâncias menores implicam menor consumo de energia e economia na implantação de serviços 
urbanos". Complementarmente, "quanto mais alto o índice, maior a dispersão das manchas urbanas", e "quanto maior a dispersão, mais baixa é a sustentabilidade da forma urbana" (Ibid.).

$\sum_{i}^{n} \frac{[D i * S I]}{R}$

Em que:

Di - distância entre o centroide da mancha urbana i e o centroide da mancha urbana principal

$\mathrm{SI}$ - área da mancha i dividida pela somatória das áreas de todas as manchas urbanas

$\mathrm{R}$ - raio do círculo correspondente à somatória das áreas das manchas urbanas

A equação 5 refere-se ao Índice de Compacidade (IC), resultante da divisão do perímetro da circunferência com área equivalente à somatória de todas as manchas urbanas pela somatória dos perímetros das manchas urbanas. Segundo Braga (2016, p. 39), "admite-se que a circunferência é a forma urbana que possibilita a maior compacidade para uma mesma densidade. Quanto mais próximo do perímetro da circunferência equivalente, mais compacta é a forma". Assim, "quanto maior o índice, maior a compacidade", e "quanto mais compacta é a forma urbana, mais alta é a sua sustentabilidade" (Ibid., p. 40).

$\sum_{i}^{n}\left[\frac{\mathrm{P}}{p i}\right]$

Em que:

$\mathrm{P}$ - perímetro da circunferência com área equivalente à somatória de todas as manchas urbanas

pi - perímetro da mancha urbana i

A equação 6 refere-se ao Índice de Descontinuidade da mancha urbana (IDes), utilizado para avaliar o quanto a mancha urbana é descontínua, sendo que, "quanto maior a descontinuidade da mancha urbana, menor será a sua sustentabilidade" (BRAGA, 2016, p. 40). O valor é dado pela proporção da somatória dos perímetros das manchas urbanas secundárias em relação à somatória dos perímetros de todas as manchas urbanas, de modo que, havendo uma única mancha, a descontinuidade é nula.

IDes. $=P d / P$

Em que:

Pd - somatória dos perímetros das manchas urbanas secundárias (descontínuas)

$\mathrm{P}$ - somatória dos perímetros de todas as manchas urbanas

Ademais, de modo a determinar o tipo de crescimento urbano predominante no período, a equação 7 foi aplicada para classificação das tipologias de crescimento urbano observadas.

Adaptada de Xu et al. (2007, p. 928), a equação 7 refere-se ao cálculo do tipo de crescimento urbano (S).

$S=\frac{L c}{P}$

Em que: 
Lc - comprimento da fronteira comum entre as áreas urbanas recém-criadas e a malha urbana anterior

$P$ - perímetro das novas manchas urbanas.

Xu et al. (2007) definem três tipologias de crescimento urbano (Infill, Edge-expansion/Extension, ou Newgenerated/Leapfrog), que podem ser caracterizadas da seguinte maneira:

- Infill - corresponde ao preenchimento de áreas localizadas predominantemente dentro da mancha urbana;

- Edge-expansion - também conhecido como Extension, trata-se da ocupação de áreas contínuas à mancha urbana;

- New-generated - também conhecido como Leapfrog, trata-se da ocupação descontínua à mancha urbana.

Assim sendo, New-generated/Leapfrog ocorre quando S é igual a 0 (zero), Edge-expansion/Extension quando o valor de $S$ for maior que 0 (zero) e menor que 0,5 , e o Infill ocorre quando o valor de $S$ é igual ou superior a 0,5 (limitado a 1);

A determinação de qual padrão foi predominante buscou verificar se houve predomínio de Infill no período. Isso porque esse é o padrão mais compacto e intensivo de crescimento urbano (XU et al., 2020), correspondendo ao preenchimento dos vazios urbanos e/ou áreas subutilizadas pré-existentes, o que indicaria uma estratégia de aumento da compacidade urbana pela intensificação no uso e ocupação do solo.

Cabe ressalva de que, para a classificação das tipologias de crescimento urbano, os fragmentos de mancha que preencheram vazios, intersticiais à mancha principal, foram automaticamente considerados como Infill $(\mathrm{S}=1)$, independentemente de seus valores de fronteira comum (LC). Quanto aos demais valores de Lc, estes foram contabilizados apenas quando observada efetiva conectividade entre fragmentos e mancha principal, tendo sido desconsiderados possíveis efeitos barreira (ocasionados por faixa de rodovias, ferrovias, APPs, corpos hídricos, etc.) que, apesar de impedirem uma conexão direta entre manchas, não contribuem para o Leapfrog.

Para a concretização do estudo foi feito levantamento bibliográfico direcionado à fundamentação teórica e à contextualização histórica da realidade urbana do município; pesquisa documental de legislações e normas municipais (planos diretores); compilação e análise de dados, via estatística descritiva (distribuição de frequências), sobre as tipologias de crescimento urbano verificadas no município, com georreferenciamento e agrupamento dos dados espaciais em um Sistema de Informações Geográficas SIG (software QGIS, versão 3.4.7 'Madeira').

No intuito de obter as variáveis necessárias para o cálculo das equações das métricas espaciais, foi necessário adicionar o arquivo shapefile com as malhas digitais dos municípios paulistas (IBGE, 2015) em um SIG, de onde foi extraído o limite municipal de São Carlos-SP. Posteriormente, foram georreferenciados e vetorizados os perímetros urbanos de 2005 e 2016, a partir dos mapas de zoneamento dos respectivos planos diretores municipais (SÃO CARLOS, 2005; 2016). Já para obtenção das manchas urbanas consideradas, recorreu-se à junção dos parcelamentos identificados por Faustino (2017), com o recorte para os períodos considerados.

Cabe salientar que, como o banco de dados dos parcelamentos englobava o período de 1857 a 2014, foi necessário identificar se houveram novas manchas urbanas em 2015 e 2016. Para isso, as camadas do perímetro urbano de 2016 e dos loteamentos existentes até 2014 foram adicionados ao software Google Earth. As imagens de satélite dos anos de 2015 e 2016 serviram de base para verificar se toda a urbanização representada nas imagens se restringia aos limites dos parcelamentos. Os indícios de novas áreas urbanas, externas a esses limites, mas ainda assim no interior da mancha urbana definida pelo perímetro urbano, foram vetorizados e incluídos no banco de dados, tendo sido identificados os parcelamentos em implantação (glebas parceladas, com arruamento identificado).

As medidas geométricas (áreas, distâncias, centroides, raios e perímetros), bem como os cálculos (comprimentos de fronteiras e somatórias) e a aplicação dos índices ocorreram em ambiente SIG, com exportação da tabela de atributos para planilhas eletrônicas. Como o método para determinação das tipologias de crescimento urbano permite uma análise individualizada por fragmento, foi feita interpolação dos valores de S (Equação 7) a partir do centroide de cada loteamento do período (2005-2016), o que possibilitou a espacialização dos valores de S. Quanto à população urbana, foram utilizados dados sobre as estimativas da população, disponibilizadas pelo IBGE (2019).

$\begin{array}{llllll}\text { Caminhos de Geografia } & \text { Uberlândia - MG } & \text { v. 22, n. } 84 & \text { dez/2021 } & \text { p. 36-55 } & \text { Página } 42\end{array}$




\section{COMPARAÇÃO TEMPORAL ENTRE RESULTADOS DAS MÉTRICAS ESPACIAIS}

No período de 2005 a 2016 houve um aumento do perímetro $(7,6 \%)$ e da mancha urbana $(2,8 \%)$ inferior ao crescimento da população urbana são-carlense $(13,5 \%)$, o que acarretou em incremento da densidade urbana, tanto da área efetivamente ocupada (10,4\%) quando do perímetro como um todo $(5,5 \%)$, conforme tabela 1. Esse crescimento das densidades é favorável ao aumento da sustentabilidade urbana, pois o adensamento contribui para "[...] promover uma otimização da infraestrutura existente, reduzindo a demanda por novas infraestruturas e a pressão sobre os orçamentos [públicos]" (SILVA; RAIA JR; FERRAZ, 2004, p. 185).

Tabela 1 - São Carlos (SP): Indicadores de forma urbana, 2005-2016

\begin{tabular}{lccc}
\hline \multicolumn{1}{c}{ Indicadores } & $\mathbf{2 0 0 5}$ & $\mathbf{2 0 1 6}$ & Incremento (\%) \\
\hline Perímetro urbano (ha.) & 8.043 & 8.651 & $7,6 \%$ \\
População urbana (hab.) & 214.786 & 243.765 & $13,5 \%$ \\
Mancha urbana (ha) & 5.126 & 5.268 & $2,8 \%$ \\
Taxa de ocupação da zona urbana - TO (\%) & $63,7 \%$ & $60,9 \%$ & $-4,5 \%$ \\
Densidade urbana da área ocupada - DU (hab./ha) & 42 & 46 & $10,4 \%$ \\
Densidade urbana do perímetro - DUP (hab./ha) & 27 & 28 & $5,5 \%$ \\
Índice de Dispersão - IDisp. & 0,385 & 0,409 & $6,1 \%$ \\
Índice de Compacidade - IC & 0,132 & 0,126 & $-5,1 \%$ \\
Índice de Descontinuidade - IDes. & 0,449 & 0,485 & $8,0 \%$ \\
\hline
\end{tabular}

Fonte: Elaboração própria (2019).

A Taxa de Ocupação (TO), por outro lado, revela um cenário menos promissor, com ociosidade de cerca de $40 \%$ da zona urbana de São Carlos-SP. Por conseguinte, a redução da TO $(-4,5 \%)$ aponta para a diminuição da ocupação da área urbana, visto o aumento do perímetro urbano não ter sido acompanhado pelo crescimento da mancha urbana (Tabela 1).

Ainda que no processo de elaboração do Plano Diretor de 2005 tenha sido constatada uma redução de cerca de $40 \%$ nos vazios urbanos (áreas não loteadas no interior do perímetro urbano) entre 2003 e $2011^{4}$ (FUSP, 2011), Barbosa (2018, p. 152) identificou, em São Carlos-SP, diversas glebas com área maior ou igual a $10.000 \mathrm{~m}^{2}$ e inseridas no perímetro urbano de 2005, que permanecem desocupadas. Logo, existem indícios de que a cidade se expandiu além do necessário para comportar sua população urbana, de modo descontínuo e com diversos vazios urbanos. Na figura 2 estão representadas as glebas, identificadas pela supramencionada autora, que continuam ociosas atualmente. Importa destacar que tais vazios se referem apenas aos considerados especulativos, isto é, foram desconsideradas as áreas livres pertencentes às Áreas de Preservação Permanente (APPs), bem como as com restrições urbanísticas (institucionais, de sistema de recreio, públicas e de bens dominicais), além dos "vazios verdes que não se incluem nas áreas verdes públicas, mas se constituem de maciços verdes” (BARBOSA, 2018, p. 88).

Figura 2 - São Carlos (SP): Crescimento urbano, 1857-2016

\footnotetext{
${ }^{4}$ De acordo com Schenk; Fantin; Peres (2016, p. 4), a utilização da Outorga Onerosa de Alteração de Uso do Solo, instrumento previsto no Estatuto da Cidade (BRASIL, 2001), contribuiu para esse preenchimento dos vazios urbanos, pois, "ao onerar a transformação de terra rural em terra urbana, incentivou a ocupação dos vazios urbanos existentes, que não demandavam outorga para serem loteados". 


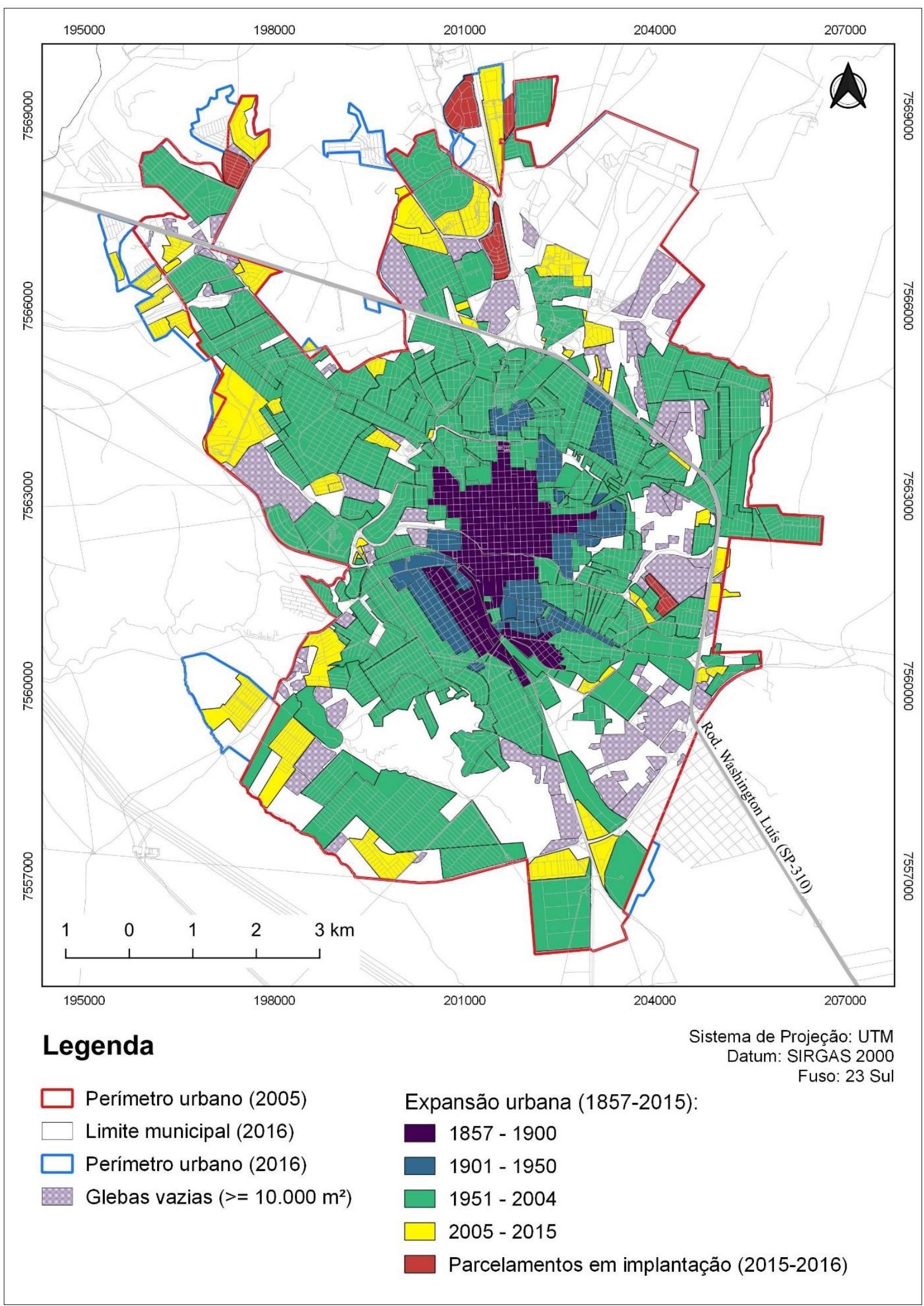

Fonte: Elaboração própria (2020), com base em dados de Faustino (2017) e de Barbosa (2018).

Embora tenha havido adensamento populacional, com a ampliação do perímetro há um estímulo à criação/permanência de vazios urbanos, que pode comprometer a sustentabilidade urbana (BRAGA, 2016) 
e elevar os custos para a provisão de infraestrutura, oferta de equipamentos e prestação de serviços públicos.

Quanto aos resultados dos indicadores de forma urbana (Tabela 1), constata-se uma ascensão da dispersão urbana $(6,1 \%)$, que se coaduna ao aumento na descontinuidade (8\%) e à diminuição da compacidade urbana $(-5,1 \%)$ no período.

De modo complementar, para Haase; Kabisch; Haase (2013), tecidos urbanos contínuos são aqueles com mais de $80 \%$ da superfície total coberta e, os descontínuos, aqueles com 30 a $80 \%$ de impermeabilização da superfície total. Logo, pelos percentuais da TO - indicador que mais se aproxima de tal definição - em ambos os períodos (2005 e 2016) haveria uma descontinuidade do tecido urbano são-carlense.

\section{PADRÕES DE CRESCIMENTO URBANO}

O anteriormente mencionado crescimento de 2,8\% na mancha urbana de São Carlos-SP no período (20052016) caracterizou-se pela distribuição dos padrões de crescimento urbano conforme figura 3 , em que estão representadas as tipologias por unidades e áreas loteadas.

Figura 3 - São Carlos (SP): Tipologias de crescimento urbano, 2005-2016

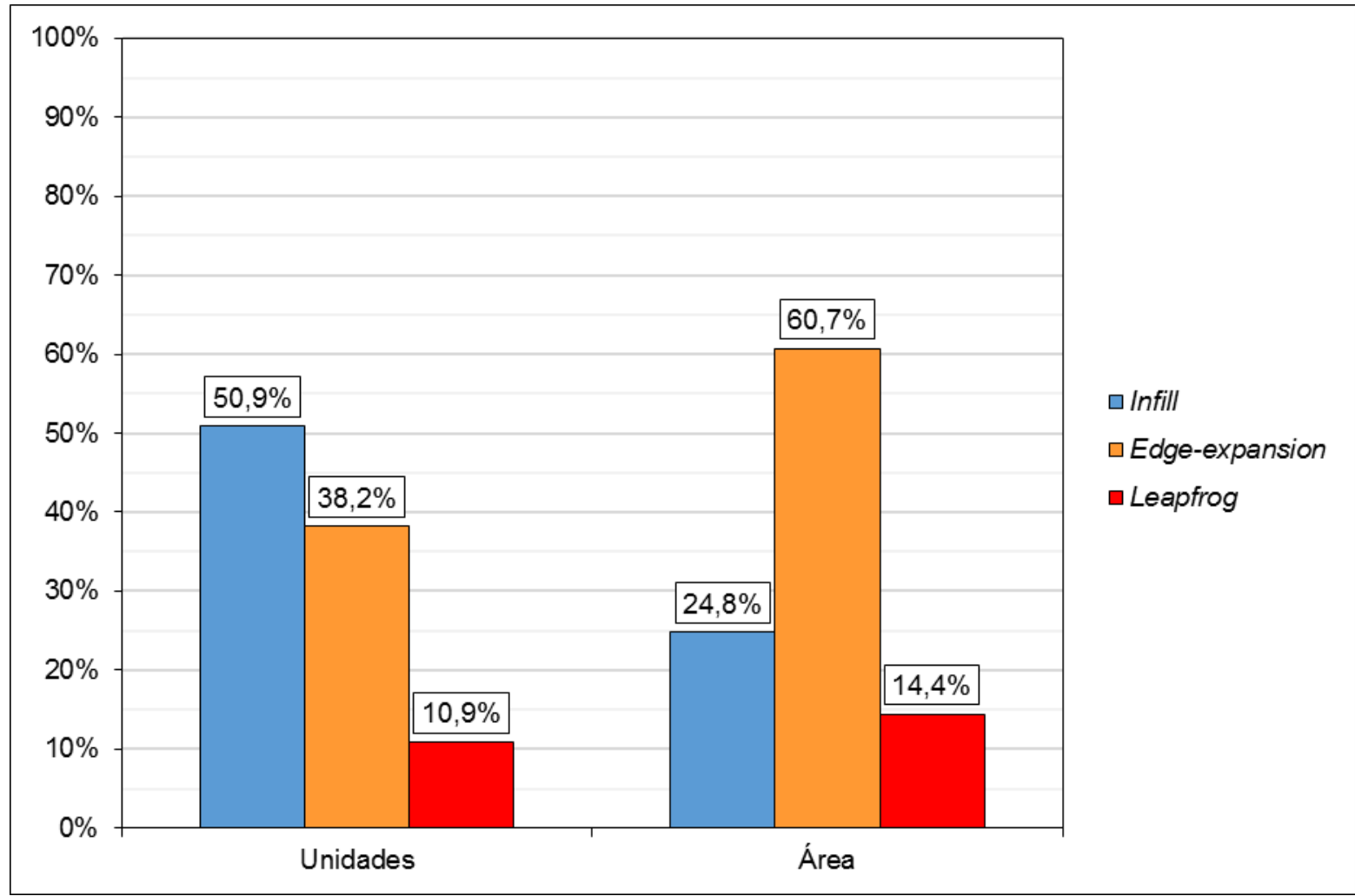

Fonte: Elaboração própria (2020)

Houveram 55 novas manchas urbanas (loteamentos) no período, sendo que 28 delas caracterizaram-se pelo padrão Infill (50,9\%), 21 por Edge-expansion (38,2\%) e seis por Leapfrog (10,9\%). Entretanto, quando se analisa as tipologias em relação ao tamanho dessas novas manchas, nota-se um predomínio do padrão Edge-expansion (60,7\%), seguido por Infill (24,8\%) e Leapfrog (14,4\%).

Portanto, embora tenha havido um maior número de unidades preenchendo vazios urbanos pré-existentes (Infill), as maiores áreas urbanizadas levaram à expansão de áreas limítrofes à mancha urbana, de tal maneira que, em relação ao tamanho das áreas, o Infill não foi o padrão predominante no período, mas sim - Edge-expansion. Essa diferença de proporções relativas às unidades e à área também se evidenciou no Leapfrog, consoante ao aumento de 8\% no Índice de Descontinuidade da mancha urbana (IDes), e de 6,1\% no Indice de Dispersão (IDisp).

\begin{tabular}{llllll}
\hline Caminhos de Geografia & Uberlândia - MG & v. 22, n. 84 & dez/2021 & p. 36-55 & Página 45
\end{tabular}


Nesse sentido, compatível com os dados de Barbosa (2018) sobre a permanência de vazios urbanos e/ou áreas subutilizadas na cidade, o preenchimento de áreas ociosas/desocupadas durante a vigência do Plano Diretor de 2005 não foi tão expressivo quanto a ocupação de áreas contínuas à malha urbana, quando se analisa o tamanho dessas novas ocupações. Isso indica que, apesar de ter havido uma intensificação no uso e ocupação do solo, a ociosidade persistiu, conforme demonstrado anteriormente pela Taxa de Ocupação (TO) em 60,9\%.

Do ponto de vista da sustentabilidade urbana, o Leapfrog seria o padrão de crescimento urbano menos desejável, sendo benéfico, portanto, que seja esta a tipologia menos expressiva, tanto quantitativamente quanto em relação ao tamanho das manchas. Ainda assim, uma predominância da tipologia Infill seria mais pertinente do que o Edge-expansion pois, para que houvesse um crescimento urbano mais compacto, o preenchimento de áreas ociosas/desocupadas necessitaria ter sido prioritário, com a expansão territorial urbana em segundo plano.

Nas figuras 4 e 5 são apresentadas as distribuições anuais das tipologias de crescimento urbano, representadas por unidades e áreas loteadas, respectivamente. Importa destacar que foram consideradas como manchas urbanas apenas os loteamentos já implantados, desconsiderando-se os parcelamentos em implantação (Figura 2), de modo que o eixo x (horizontal) registra apenas o período de 2005 a 2015.

Figura 4 - São Carlos (SP): Tipologias de crescimento urbano anual por unidades loteadas, 2005-2016

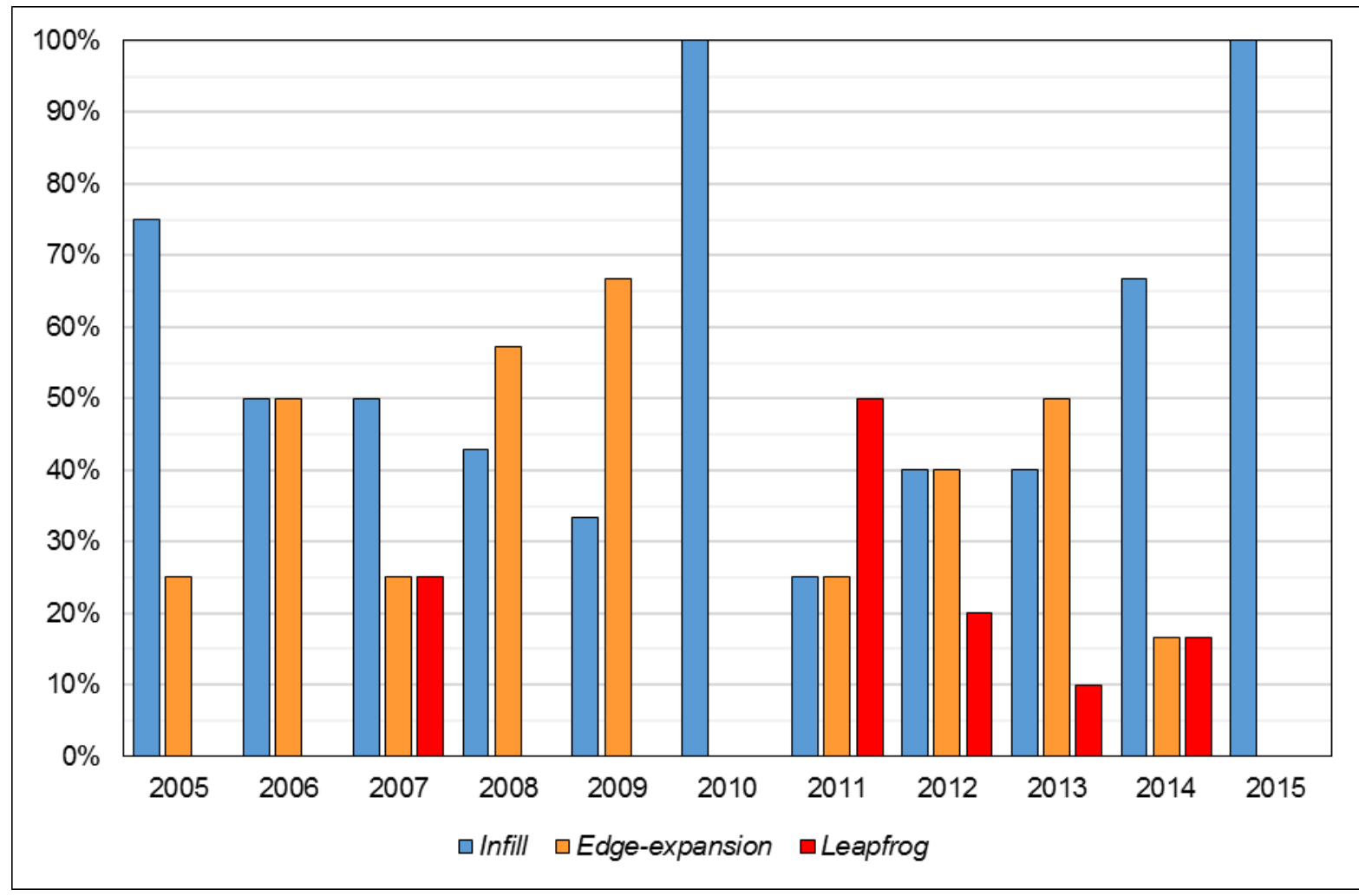

Fonte: Elaboração própria (2020).

Figura 5 - São Carlos (SP): Tipologias de crescimento urbano anual por áreas loteadas, 2005-2016

$\begin{array}{llllll}\text { Caminhos de Geografia } & \text { Uberlândia - MG } & \text { v. 22, n. } 84 & \text { dez/2021 } & \text { p. 36-55 } & \text { Página } 46\end{array}$




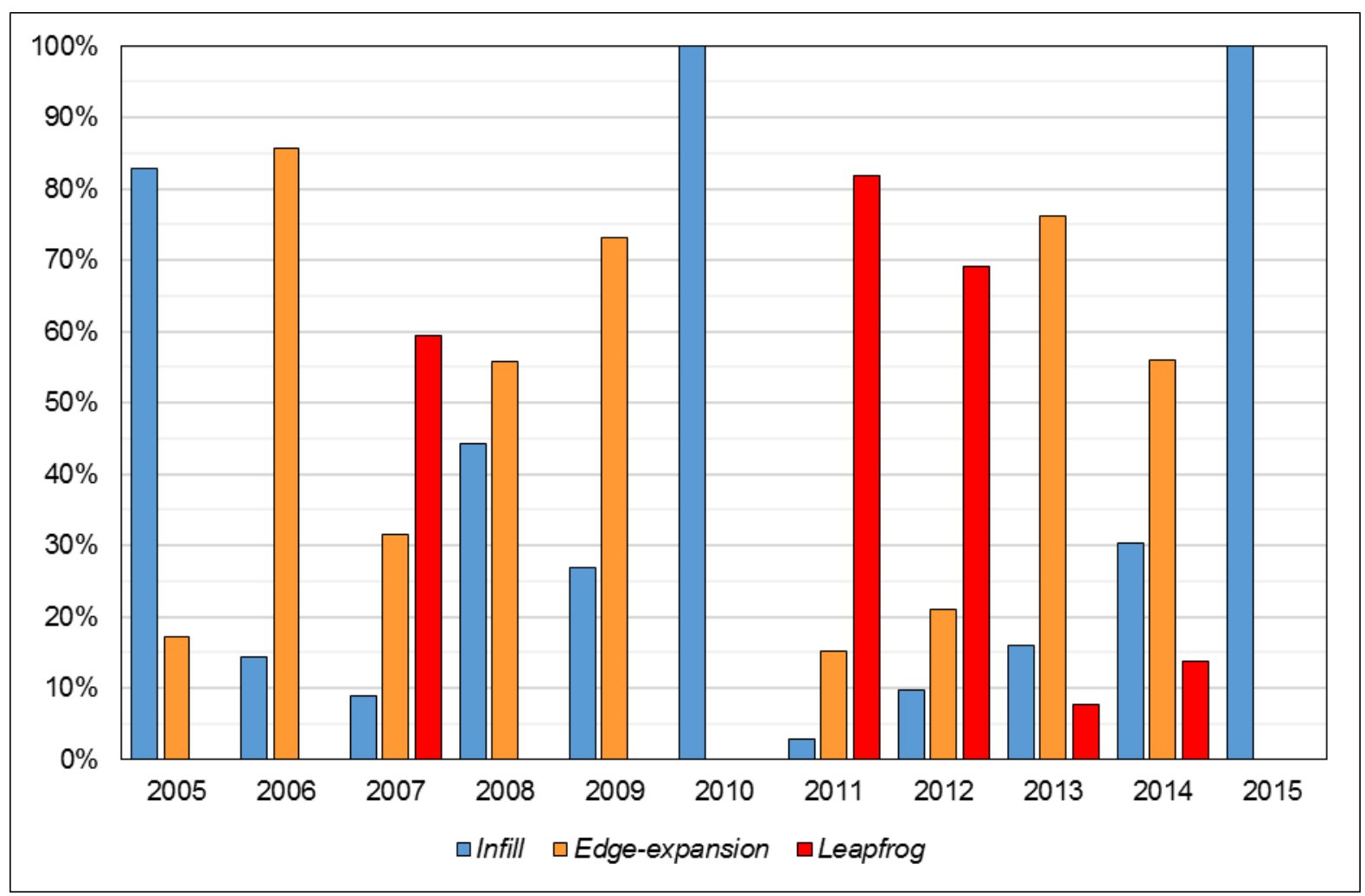

Fonte: Elaboração própria (2020).

Percebe-se que, embora em 2006 o número de unidades loteadas tenha sido uniforme entre Infill e Edgeexpansion (Figura 4), quando se analisa pelo tamanho das áreas, o Edge-expansion se sobressai (Figura 5). Similarmente, embora em 2007 o número de unidades loteadas tenha sido uniforme entre Edgeexpansion e Leapfrog (Figura 4), quando se analisa pelo tamanho das áreas o Leapfrog se destaca (Figura 5), sobrelevando-se até mesmo em relação ao Infill, que predominava em número de unidades. Em 2014 também ocorre essa distribuição igualitária entre Edge-expansion e Leapfrog por número de unidades loteadas, contudo, é o Edge-expansion que se sobressai quando a análise é feita pelo tamanho das áreas, ultrapassando o anteriormente predominante Infill, de acordo com as figuras 4 e 5, respectivamente.

Em 2011 e 2012 havia uma distribuição igualitária entre Infill e Edge-expansion em relação ao número de unidade loteadas (Figura 4). Contudo, em ambos os casos o Leapfrog foi majoritário na análise por área (Figura 5), sendo tal divergência mais acentuada em 2012, ano em que o Leapfrog era o padrão menos representativo no quantitativo de unidades.

Os padrões que se mantiveram constantes, isto é, com proporções maiores tanto em relação à quantidade de unidades quanto às áreas loteadas ocorreram em 2005, 2008, 2009 e 2013. Os únicos anos em que houve apenas Infill foram 2010 e 2015.

A espacialização dos valores de $S$ resultou na figura 6 , em que se verifica a disposição dos diferentes tipos de crescimento urbano identificados. Nota-se que, exceto pela região sudeste, houve crescimento urbano do tipo Edge-expansion em todas as demais direções, com Leapfrog nas regiões leste e sudoeste, porém mais concentrado na região noroeste.

Figura 6 - São Carlos (SP): Espacialização das tipologias de crescimento urbano, 2005-2015

$\begin{array}{llllll}\text { Caminhos de Geografia } & \text { Uberlândia - MG } & \text { v. 22, n. } 84 & \text { dez/2021 } & \text { p. 36-55 } & \text { Página } 47\end{array}$




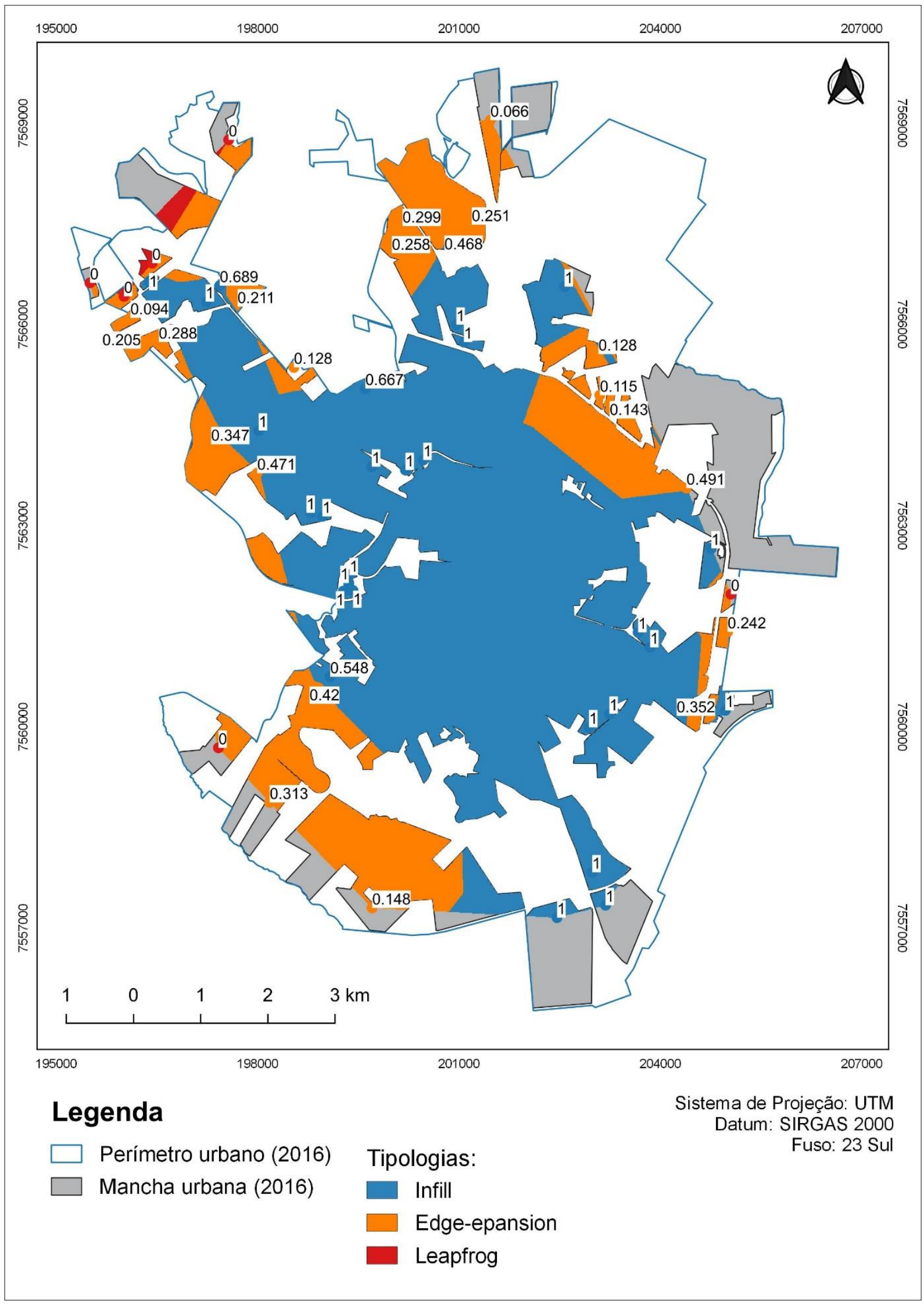

Fonte: Elaboração própria (2020).

\section{CONFIGURAÇÃO ESPACIAL E PRODUÇÃO DO ESPAÇO URBANO}


Os resultados dos indicadores aplicados assinalaram um incremento das densidades no período de 2005 a 2016, demonstrado por um aumento do perímetro e da mancha urbana inferior ao crescimento da população urbana são-carlense. Ainda assim, a densidade de São Carlos-SP, representada tanto pela DU quanto pela DUP, está abaixo do limiar de 90 hab./ha, considerado o ponto de densidade ideal por Libertun de Duren e Compeán (2016). Para tais autores, existiria uma relação (em forma de $U$ ) entre densidade e gastos per capita em serviços públicos, de modo que o adensamento traria vantagens de eficiência na provisão de serviços públicos até certo ponto ideal: 9.000 hab./km² (LIBERTUN DE DUREN; COMPEÁN, 2016).

Ademais, cabe ressaltar que o adensamento é apenas um dos elementos constituintes da forma urbana (GÜNERALP et al., 2017), tendo sido acompanhado, neste caso, por uma ocupação mais rarefeita do território (dispersão), com aumento da descontinuidade da mancha urbana e diminuição da compacidade urbana. Constatou-se, também, que o crescimento urbano se pautou, predominantemente, pela expansão territorial, pois, embora tenha havido o preenchimento de vazios urbanos pré-existentes (Infill), em relação ao tamanho dos loteamentos houve maiores áreas urbanizadas expandindo a mancha urbana (Edgeexpansion). Ademais, considerada um dos principais vetores de expansão e valorização imobiliária na cidade (BARCELLA e MELAZZO, 2020), a região noroeste foi a que aglutinou a maior parte do Leapfrog identificado.

Visto a habitual associação entre crescimento populacional e urbanização, tais resultados supramencionados podem parecer paradoxais, entretanto, já existem abordagens que oferecem perspectivas mais amplas sobre o assunto. Nesta vertente, Marandola Jr. et al. (2013, p. 36) apontam para a necessidade de superação do que denominam de uma "simplificação rasteira", que leva à "responsabilização do crescimento populacional aos próprios males de uma nítida expansão sem limites", desmistificando a simplificada vinculação entre crescimento demográfico e degradação ambiental (LAMBIN et al., 2001; OJIMA, 2011; MELLO e SATHLER, 2015).

É importante destacar, portanto, que a expansão urbana é "uma materialização territorial das decisões e dinâmicas dos atores sobre a alocação e gestão do uso da terra" (PAGLIARIN, 2018, p. 3664, tradução própria), que se articula à uma tendência generalizada de desregulamentação (JIMÉNEZ et al., 2018) e se apresenta "como parte e decorrência do processo de produção do espaço urbano, a partir de interesses fundiários e imobiliários" (SILVA, 2009, p. 190). Isso porque "a incorporação de novas terras à malha urbana altera o gradiente de preços que expressa as diferentes rendas fundiárias auferidas na cidade" (SANTOS, 2012, p. 67). Assim, devido à condição de mercadoria assumida pelas "cidades produzidas sob a lógica capitalista" (BARBOSA e COSTA, 2012, p. 478), a produção do solo urbano se apoia na especulação imobiliária, sendo que, "nos vazios criados entre a malha urbana e o[s] loteamento[s] ocorre uma valorização dos imóveis" (SILVA, 2009, p. 200). Por conseguinte, a retenção de terrenos ociosos torna-se oportuna pela expectativa de valorização futura (HIDALGO; VOLKER; RAMÍREZ, 2014, p. 02, tradução própria), com a urbanização dispersa se articulando à grande quantidade de vazios urbanos (SILVA; RAIA JR; FERRAZ, 2004).

Logo, as aproximações entre o crescimento urbano disperso e horizontal com as características físicas do território não explicam, por si só, a forma urbana. Além do que, a expansão territorial urbana não se articula somente ao aumento da população, associando-se aos processos de acumulação capitalista e decorrendo do modo como ocorre a valorização da terra e sua apropriação diferenciada pelas camadas sociais. Desta forma, "para os agentes produtores do espaço urbano, quanto mais a cidade cresce, maiores também são as possibilidades efetivas de tais agentes auferirem ganhos com o crescimento" (BARBOSA e GOMES, 2016, p. 334). Em vista disso, a configuração espacial das cidades vincula-se às necessidades de "assegurar a reprodução e acumulação de capital por meio do setor imobiliário", visto o papel de "amortizador de crises cíclicas do capitalismo" (Ibid., p. 338), desempenhado por esse setor ${ }^{5}$.

No Brasil, o padrão disperso de urbanização agravou-se nos últimos anos, em função "do aquecimento do mercado imobiliário, sobretudo no período de 2009-2014" (BARBOSA e GOMES, 2016, p. 339), como resultado de diversas circunstâncias nacionais que se refletiram na expansão territorial das cidades brasileiras. Como elementos recentes que contribuíram para esse fenômeno, visando combater a crise econômica de 2008 e atender aos interesses da indústria da construção civil, destaca-se: o aumento da oferta de crédito imobiliário via bancos oficiais; a criação do Programa Minha Casa Minha Vida (PMCMV), consoante à mobilização de fundos públicos e semi-públicos que, além de fortalecerem a produção e o consumo de imóveis, movimentou toda cadeia produtiva do setor da construção civil; as mudanças

\footnotetext{
5 "Os capitais de outros segmentos econômicos encontram no imobiliário uma espécie de refúgio, por ocasião de crises econômicas, contudo, também nas fases de expansão, é um dos segmentos da economia que mais absorvem investimentos e estimulam outros que se relacionam com ele [...]" (BARBOSA; COSTA, 2012, p. 338).

$\begin{array}{llllll}\text { Caminhos de Geografia } & \text { Uberlândia - MG } & \text { v. 22, n. } 84 & \text { dez/2021 } & \text { p. 36-55 } & \text { Página } 49\end{array}$
}


institucionais e regulamentações jurídicas favoráveis aos credores, que contribuíram para garantia da segurança jurídica nas transações financeiras de imóveis (SOUZA, 2015; COSTA e NASCIMENTO, 2016).

Segundo Ribeiro; Holanda; Coelho (2012), de modo geral, este processo de dispersão urbana foi, inicialmente, caracterizado pela ocupação periférica associada à favelização, mas, atualmente, é acentuado pela busca de qualidade de vida por populações de média e alta rendas, o "[...] que se traduz em grandes terrenos em ocupações horizontais (eventualmente verticalizadas) cercadas [...]" (Ibid., p. 235). Por conseguinte, com a implantação dos espaços residenciais fechados (GOES e SPOSITO, 2014), houve o agravamento da tendência de crescimento horizontal nas cidades não metropolitanas (SANTORO; COBRA; BONDUKI, 2010), com "fragmentação territorial e social do espaço urbano" (BARBOSA e COSTA, 2011, p. 59-60).

Sobre a produção do espaço urbano em cidades médias, destaca-se a existência de diversas contribuições que discutem a relação entre expansão territorial urbana e os interesses imobiliários, especificamente no caso são-carlense, aprofundando-se sobre seus desdobramentos na ampliação das desigualdades socioespaciais (DAL POZZO, 2012; SILVA, 2017; BARCELLA. 2019; BARCELLA e MELAZZO, 2020). Além de trabalhos que abordam as forças atuantes no processo de revisão do Plano Diretor de São Carlos-SP, com destaque para os discursos dos agentes envolvidos nas diferentes propostas de expansão urbana (SCHENK; FANTIN; PERES, 2015; SCHENK; FANTIN; PERES, 2016; FANTIN; SCHENK; PERES, 2017).

Por fim, Neuman $(2005$, p. 22, tradução própria) destaca que "a forma é tanto a estrutura que molda o processo quanto a estrutura que emerge do processo". Diante disso, a configuração espacial por si só não determina a sustentabilidade de uma cidade, pois seu processo de urbanização também precisa ser sustentável. Isto posto, conceber a forma urbana como decorrência processual da maneira como as áreas urbanas se desenvolvem requer admitir que a produção do espaço interfere na sustentabilidade urbana. Por conseguinte, "é necessário desfocar o crescimento populacional em si, enfatizando o modelo de urbanização e as políticas de desenvolvimento urbano" (MARANDOLA JR. et al., 2013, p. 51).

\section{CONSIDERAÇÕES FINAIS}

No decorrer deste artigo, foi feita uma avaliação espacial da expansão territorial urbana em uma cidade média do interior paulista, por meio da mensuração das transformações na forma urbana, e da categorização das tipologias de crescimento urbano identificadas. A partir disso, discutiu-se as relações entre forma urbana e produção do espaço urbano, sendo que o período analisado correspondeu à vigência do primeiro Plano Diretor de São Carlos-SP (2005), revisado em 2016. O intuito foi compreender a relação entre a produção do espaço urbano em cidades médias com a configuração espacial (características espaciais do ambiente urbano), sob a perspectiva da sustentabilidade ambiental, tendo como pressuposto a relevância do tema àqueles que analisam os processos de urbanização contemporânea.

Constatou-se que houve adensamento, ocupação urbana dispersa, aumento da descontinuidade da mancha urbana e diminuição da compacidade, com expansão das bordas do tecido urbano pelo aumento da área urbanizada durante a vigência do Plano Diretor do município em questão (2005 a 2016). Tais fenômenos podem ser associados (mas não limitados) à atuação do mercado imobiliário, que nos últimos anos tem pautado a expansão periférica das cidades médias pela acentuação da valorização diferenciada, expressa na coexistência entre habitação social de mercado e condomínios fechados, revelando os mais recentes contornos da segregação residencial, paralelo à permanência de interesses fundiários via retenções especulativas, materializadas nos vazios urbanos.

Por intermédio de uma abordagem metodológica para análise espacial e classificação do padrão de crescimento urbano, foram realizadas avaliações quantitativas sobre dimensões e fenômenos usualmente explorados qualitativamente. Os valores encontrados, apesar de suas limitações, funcionam como indicadores que podem subsidiar diagnósticos sobre a expansão territorial urbana em determinado período, sendo adequados para avaliação da sustentabilidade da urbanização, ao identificar os padrões de crescimento urbano. Como limitação, entretanto, cabe destacar que a perspectiva aqui exposta, devido a seu caráter físico e quantitativo, desconsidera aspectos quantitativos relevantes, como o papel da multiplicidade de usos. Embora isso não invalide a importância das dimensões da forma urbana, poderia proporcionar uma concepção imprecisa. Isso porque, a despeito de formas urbanas mais dispersas serem atreladas aos usos do solo espacialmente segregados, um adensamento mais elevando, por si só, é insuficiente para reduzir viagens motorizadas, por exemplo, sendo oportuno conciliá-lo com usos múltiplos, pois a separação de usos inerentemente motiva deslocamentos. Logo, tal limitação implica na necessidade de avanços metodológicos para incorporação desse aspecto relacionado não a forma, mas à função. 
Estudos futuros poderiam aproximar o crescimento horizontal e disperso identificado com as condicionantes do meio físico capazes de auxiliar na apreensão da expansão territorial urbana, em articulação com diferenciações de classes, reproduzidas pelas dinâmicas contraditórias do mercado imobiliário formal. Adicionalmente, também existe a possibilidade de se avançar no sentido de agregar as análises, englobando compacidade, dispersão e descontinuidade de maneira integrada em um único índice, no intuito de representar a realidade de modo holístico, minimizando possíveis vieses das análises, atualmente dissociadas e que exigem um conhecimento aprofundado da realidade local por parte dos(as) responsáveis pela análise da realidade apurada. Ainda assim, salienta-se que os métodos empregados possibilitam a realização de análises comparativas, pela padronização dos resultados empíricos e a confrontação dos mesmos com a realidade.

\section{AGRADECIMENTOS}

O presente trabalho foi realizado com apoio da Coordenação de Aperfeiçoamento de Pessoal de Nível Superior - Brasil (CAPES) - Código de Financiamento 001.

\section{REFERÊNCIAS}

ABRAMO, P. A cidade com-fusa: a mão inoxidável do mercado e a produção da estrutura urbana nas grandes metrópoles latino-americanas. Revista Brasileira de Estudos Urbanos e Regionais, v. 5, n. 2, p. 12-32, 2007.

ANGEL, S.; BLEI, A. M.; PARENT, J.; LAMSON-HALL, P.; SÁNCHEZ, N. G.; CIVCO, D. L.; LEI, R. Q.; THOM, K. Atlas of Urban Expansion - 2016 Edition, Volume 1: Areas and Densities. New York: New York University, Nairobi: UN-Habitat, and Cambridge, MA: Lincoln Institute of Land Policy, 2016.

ARTMANN, M.; INOSTROZA, L.; FAN, P. Urban sprawl, compact urban development and green cities. How much do we know, how much do we agree? Ecological Indicators, v. 96, p. 3-9, 2019.

BARBOSA, A. G.; COSTA, A. A. Implicações socioespaciais, econômicas e jurídicas em condomínios fechados horizontais. Mercator, v. 10, n. 21, p. 49-61, 2011.

O solo urbano e a apropriação da natureza na cidade. Sociedade \& Natureza, v. 24, n. 3, p. 477-488, dez. 2012.

BARBOSA, A. G.; GOMES, E. T. A. Reflexão sobre o papel do setor imobiliário na acumulação urbana. Sociedade \& Natureza, v. 28, n. 3, p. 333-346, dez. 2016.

BARBOSA, Y. B. Análise temporal do processo de ocupação dos vazios urbanos no município de São Carlos, SP: sob a ótica de uma cidade compacta. Tese (Doutorado em Engenharia Urbana) - São Carlos: UFSCar, 2018.

BARCELLA, B. L. A interescalaridade da produção habitacional do programa Minha Casa Minha Vida em cidades médias: do aumento do consumo imobiliário ao aumento das desigualdades socioespaciais.

Caderno Prudentino de Geografia, v. 4, n. 41, p. 33-59, 2019.

BARCELLA, B. L. S.; MELAZZO, E. S. Expansão urbana e dinâmica imobiliária: comparando as estratégias fundiárias dos agentes imobiliários em cidades médias. Sociedade \& Natureza, v. 32, p. 108125, 2020.

BRAGA, R. Avaliação da sustentabilidade da expansão do perímetro urbano da cidade de Piracicaba - SP por meio de indicadores de forma urbana. Geografia, Ensino \& Pesquisa, v. 20, n. 2, p. 33-44, 2016.

BRASIL. Lei no 10.257, de 10 de julho de 2001. Disponível em: https://www.planalto.gov.br/ccivil_03/Leis/LEIS_2001/L10257.htm. Acesso em 24 de julho de 2020.

COELHO, T. A. S. Análise geoespacial e mapeamento da densidade de pontos de alagamento em vias públicas do município de São Paulo, entre 2008 e 2013. Dissertação (Mestrado em Geografia) Campinas: Unicamp, 2016

COSTA, A. A.; NASCIMENTO, E. A. A produção de espaço urbano e os fatores do processo de expansão do mercado imobiliário em Mossoró-RN. Ateliê Geográfico, v. 10, n. 2, p. 21-41, 2016.

DAL POZZO, C. F. Fragmentação socioespacial em cidades de porte médio. Revista da ANPEGE, v. 8 , n. 9, p. 29-46, 2012. 
DEUS, L. R.; SANCHES, S. P. Influência da forma urbana sobre o comportamento de viagens urbanas. Caminhos de Geografia, v. 9, n. 29, p. 1-16, 2009.

FANTIN, M.; SCHENK, L. B. M.; PERES, R. B. Propostas de expansão urbana para o Plano Diretor de São Carlos (SP): um olhar sob o prisma das limitações dos meios físico e biótico. In: PEREZ FILHO, A; AMORIM, R. R. (Eds.). Os desafios da Geografia Física na fronteira do conhecimento. Campinas: Instituto de Geociências, Universidade Estadual de Campinas, 2017. p. 6577-6590

FAUSTINO, A. S. Gestão de águas pluviais urbanas através da abordagem Water Sensitive Urban Design: desafios e potencialidades para o município de São Carlos - SP. Dissertação (Mestrado em Engenharia Urbana) - São Carlos: UFSCar, 2017.

FOLEY, J. A.; DEFRIES, R.; ASNER, G. P.; BARFORD, C.; BONAN, G.; CARPENTER, S. R.; CHAPIN, F. S.; COE, M. T.; DAILY, G. C.; GIBBS, H. K.; HELKOWSKI, J. H.; HOLLOWAY, T.; HOWARD, E. A.; KUCHARIK, C. J.; MONFREDA, C.; PATZ, J. A.; PRENTICE, I. C.; RAMANKUTTY, N.; SNYDER, P. K. Global consequences of land use. Science, v. 309, n. 5734, p. 570-574, 2005.

FUSP - Fundação de Apoio à Universidade de São Paulo. Revisão do plano diretor do município de São Carlos. Produto I - Atualização da Leitura Técnica do Município. 2011.

GOES, E. M.; SPOSITO, M. E. B. A insegurança e as novas práticas espaciais em cidades brasileiras. Scripta Nova. Revista Electrónica de Geografía y Ciencias Sociales, v. 18, n. 493(54), p. 1-16, 2014.

GRIMM, N. B.; FAETH, S. H.; GOLUBIEWSKI, N. E.; REDMAN, C. L.; WU, J. G.; BAI, X.; BRIGGS, J. M. Global change and the ecology of cities. Science, v. 319, n. 5864, p. 756-760, 2008.

GÜNERALP, B.; ZHOU, Y.; ÜRGE-VORSATZ, D.; GUPTA, M.; YU, S.; PATEL, P. L.; FRAGKIAS, M.; LI, X.; SETO, K. C. Global scenarios of urban density and its impacts on building energy use through 2050. PNAS, v. 114, n. 34, p. 8945-8950, 2017.

HAASE, D.; KABISCH, N.; HAASE, A. Endless Urban Growth? On the Mismatch of Population, Household and Urban Land Area Growth and Its Effects on the Urban Debate. PLoS ONE, v. 8, n. 6, e66531, 2013.

HIDALGO, R.; VOLKER, P.; RAMÍREZ, N. La ciudad inmobiliaria: mecanismos institucionales, relaciones de poder y mercantilización del medio natural. El caso del área metropolitana de Valparaíso. Scripta Nova. Revista Electrónica de Geografía y Ciencias Sociales, v. 18, n. 493(34), 2014.

IBGE - Instituto Brasileiro de Geografia e Estatística. IBGE - Cidades. São Carlos. Disponível em: https://cidades.ibge.gov.br/brasil/sp/sao-carlos/panorama. Acesso em: 27 de setembro de 2021.

Estimativas da População. Downloads. Disponível em:

https://www.ibge.gov.br/estatisticas/sociais/populacao/9103-estimativas-depopulacao.html?edicao=17283\&t=downloads. Acesso em: 03 de julho de 2019.

Mapas. Bases e referenciais. Bases cartográficas. Malhas digitais. Municipal. 2015. Disponível em: https://mapas.ibge.gov.br/bases-e-referenciais/bases-cartograficas/malhas-digitais.html; Acesso em: 06 de junho de 2019.

JIMÉNEZ, V.; HIDALGO, R.; CAMPESINO, A-J.; ALVARADO, V. Normalización del modelo neoliberal de expansión residencial más allá del límite urbano en Chile y España. EURE, v. 44, n. 132, p. 27-46, 2018.

JONES, K. E.; PATEL, N. G., LEVY, M. A.; STOREYGARD, A.; BALK, D.; GITTLEMAN, J. L.; DASZAK, P. Global trends in emerging infectious diseases. Nature, v. 451, p. 990-993, 2008.

KRAFTA, R.; SILVA, E. L. B. Detecção de padrões da forma urbana: quadro geral e um caso. Urbe. Revista Brasileira de Gestão Urbana, v. 12, e20190209, 2020.

LAMBIN, E. F.; TURNER, B. L.; GEIST, H. J.; AGBOLA, S. B.; ANGELSEN, A.; BRUCE, J. W.; COOMES, O. T.; DIRZO, R.; FISCHER, G.; FOLKE, C.; GEORGE, P. S.; HOMEWOOD, K.; IMBERNON, J.; LEEMANS, R.; LI, X.; MORAN, E. F.; MORTIMORE, M.; RAMAKRISHNAN, P. S.; RICHARDS, J. F.; SKANES, H.; STEFFEN, W.; STONE, G. D.; SVEDIN, U.; VELDKAMP, T. A.; VOGEL, C.; XU, J. The causes of land-use and land-cover change: moving beyond the myths. Global Environmental Change, v. 11, p. 261-269, 2001.

LIBERTUN DE DUREN, N.; COMPEÁN, R. G. Growing resources for growing cities: Density and the cost of municipal public services in Latin America. Urban Studies, v. 53, n. 14, p. 3082-3107, 2016.

LIU, X.; HUANG, Y.; XU, X.; LI, X.; LI, X; CIAIS, P.; LIN, P.; GONG, K.; ZIEGLER, A. D.; CHEN, A.; GONG, P.; CHEN, J; HU, G.; CHEN, Y.; WANG, S.; WU, Q.; HUANG, K., ESTES, L.; ZENG, Z. High-

$\begin{array}{llllll}\text { Caminhos de Geografia } & \text { Uberlândia - MG } & \text { v. 22, n. } 84 & \text { dez/2021 } & \text { p. 36-55 } & \text { Página } 52\end{array}$


spatiotemporal-resolution mapping of global urban change from 1985 to 2015. Nature Sustainability, v. 3, p. 564-570, 2020.

MARANDOLA JR., E.; MARQUES, C.; PAULA, L. T.; CASSANELI, L. B. Crescimento urbano e áreas de risco no litoral norte de São Paulo. Revista Brasileira de Estudos de População, v. 30, n. 1, p. 35-56, 2013.

MARTILLI, A. An idealized study of city structure, urban climate, energy consumption, and air quality. Urban Climate, v. 10, p. 430-446, 2014.

MARTINE, G. O lugar do espaço na equação população/meio ambiente. Revista Brasileira de Estudos de População, v. 24, n. 2, p. 181-190, 2007.

MELLO, L. F.; SATHLER, D. A demografia ambiental e a emergência dos estudos sobre população e consumo. Revista Brasileira de Estudos de População, v. 32, n. 2, p. 357-380, 2015.

MITLIN, D.; SATTERTHWAITE, D. Sustainable Development and Cities. In: PUGH, C. (Ed.).

Sustainability, the Environment and Urbanization. London: Earthscan Publications Limited, 2002. p. 2361.

NAVARRO VERA, J. R.; ORTUÑO PADILLA, A. Aproximación a la génesis de la contribución de la densidad en la noción de "ciudad compacta". EURE, v. 37, n. 112, p. 23-41, 2011.

NEUMAN, M. The Compact City Fallacy. Journal of Planning Education and Research, v. 25, n. 1, p. 11-26, 2005.

OJIMA, R. As dimensões demográficas das mudanças climáticas: cenários de mudança do clima e as tendências do crescimento populacional. Revista Brasileira de Estudos de População, v. 28, n. 2, p. 389-403, 2011.

Novos contornos do crescimento urbano brasileiro? O conceito de urban sprawl e os desafios para o planejamento regional e ambiental. GEOgraphia, v. 10, n. 19, p. 46-59, 2008.

PAGLIARIN, S. Linking processes and patterns: Spatial planning, governance and urban sprawl in the Barcelona and Milan metropolitan regions. Urban Studies, v. 55, n. 16, p. 3650-3668, 2018.

PEREIRA, R. H. M.; NADALIN, V. G.; GONÇALVES, C. N.; \& NASCIMENTO, I. F. ODS 11: Tornar as Cidades e os Assentamentos Humanos Inclusivos, Seguros, Resilientes e Sustentáveis. O que mostra o retrato do Brasil?. Cadernos ODS. Brasília: IPEA, 2019. Disponível em:

http://www.ipea.gov.br/portal/images/stories/PDFs/livros/livros/190612_cadernos_ODS_objetivo_11.pdf. Acesso em: 09 de setembro de 2019.

PERES, R. B. O planejamento regional e urbano e a questão ambiental: análise da relação entre o plano de bacia hidrográfica Tietê-Jacaré e os planos diretores municipais de Araraquara e São Carlos, SP. Tese (Doutorado em Engenharia Urbana) - São Carlos: UFSCar, 2012.

RIBEIRO, R.; HOLANDA, F.; COELHO, J. Índices de qualidade configuracional urbana. O caso do Distrito Federal, Brasil. EURE, v. 38, n. 114, p. 229-255, 2012.

ROCKSTRÖM, J.; STEFFEN, W.; NOONE, K.; PERSSON, A.; CHAPIN III, F. S.; LAMBIN, E. F.; LENTON, T. M.; SCHEFFER, M.; FOLKE, C.; SCHELLNHUBER, H. J.; NYKVIST, B.; WIT, C. A.; HUGHES, T.; LEEUW, S.; RODHE H.; SÖRLIN, S.; SNYDER, P. K.; COSTANZA, R.; SVEDIN, U.; FALKENMARK, M.; KARLBERG, L.; CORELL, R. W.; FABRY, V. J.; HANSEN, J.; WALKER, B.; LIVERMAN, D.; RICHARDSON, K.; CRUTZEN, P.; FOLEY, J. A. A safe operating space for humanity. Nature, v. 461, n. 24, p. 472-475, 2009.

SANTORO, P. F.; COBRA, P. L.; BONDUKI, N. Cidades que crescem horizontalmente: 0 ordenamento territorial justo da mudança de uso rural para urbano. Cadernos Metrópole, São Paulo, v. 12, n. 24, p. 417-440, 2010.

SANTOS, E. O. Propriedade privada da terra e expansão urbana: o caso da concentração fundiária na implantação de loteamentos em Fortaleza (1930-2000). Ateliê Geográfico, v. 6, n. 4, p. 61-87, 2012.

SÃO CARLOS. Prefeitura Municipal. Plano Local de Habitação de Interesse Social de São Carlos PLHIS. Etapa 2. Diagnóstico - Parte 1. Contexto. São Carlos: Teia Casa de Criação/PROHAB, 2010. Disponível em: http://www.saocarlos.sp.gov.br/index.php/plhis-sao-carlos.html. Acesso em: 06 de junho de 2019. 
. Prefeitura Municipal. Lei no 13.691, de 25 de novembro de 2005. Institui o Plano Diretor do Município de São Carlos e dá outras providências. Disponível em:

https://leismunicipais.com.br/a/sp/s/sao-carlos/lei-ordinaria/2005/1370/13691/lei-ordinaria-n-13691-2005institui-o-plano-diretor-do-municipio-de-sao-carlos-e-da-outras-providencias. Acesso em 24 de julho de 2020.

Prefeitura Municipal. Lei no 18.053, de 19 de dezembro de 2016. Estabelece o Plano Diretor do Município de São Carlos, e dá outras providências. Disponível em:

https://leismunicipais.com.br/a/sp/s/sao-carlos/lei-ordinaria/2016/1805/18053/lei-ordinaria-n-18053-2016estabelece-o-plano-diretor-do-municipio-de-sao-carlos-e-da-outras-providencias. Acesso em 24 de julho de 2020.

SCHENK, L. M. B.; FANTIN, M.; PERES, R. B. Agentes produtores e forma urbana: a trajetória do Núcleo Gestor Compartilhado no processo de revisão do Plano Diretor Municipal de São Carlos, SP. In: Colóquio QUAPA SEL - Sistemas de Espaços Livres: transformações e permanências no século XXI, 11., 2016, Salvador, BA. Anais [...]. Salvador: UFBA, 2016.

A revisão do plano diretor da cidade de São Carlos e as novas formas urbanas em curso. In: Colóquio Quapá-SEL - Produção e apropriação dos espaços livres e da forma urbana, 9., 2015, Brasília. Anais [...]. Brasília: Fauunb-Brasília, 2015.

SEADE - Fundação Sistema Estadual de Análise de Dados. Perfil dos municípios paulistas. 2019. Disponível em: http://www.perfil.seade.gov.br/. Acesso em: 06 de junho de 2019.

SETO, K. C.; FRAGKIAS, M.; GÜNERALP, B., REILLY, M. K. A Meta-Analysis of Global Urban Land Expansion. PLoS ONE, v. 6, n. 8, e23777, 2011.

SETO, K. C.; SHEPHERD, J. M. Global urban land-use trends and climate impacts. Current Opinion in Environmental Sustainability, v. 1, n. 1, p. 89-95, 2009.

SINGER, P. O uso do solo urbano na economia capitalista. Boletim Paulista de Geografia. São Paulo, n. 57, p. 77-92, 1980.

SILVA, A. N. R.; RAIA JR, A. A.; FERRAZ, A. C. P. Minimising the Negative Effects of Urban Sprawl: Towards a Strategy for Brazil. In: JENKS, M.; BURGESS, R. (Eds.). Compact Cities: Sustainable Urban Forms for Developing Countries. Taylor \& Francis e-Library, 2004. p. 183-192.

SILVA, B. L. B. Entre o geral e o particular: comparação entre os mercados fundiários das cidades de Ribeirão Preto (SP) e São Carlos (SP). Revista Geografia e Pesquisa, v. 11, n. 1, p. 49-63, 2017.

SILVA, R. B. A expansão territorial urbana e o Programa de Desfavelamento e Loteamentos Urbanizados. Caminhos de Geografia, v. 10, n. 30, p. 187-204, 2009.

SOUZA, L. B. A hipérbole mercantil da expansão urbana e suas implicações ambientais. Mercator, v. 14, n. 4, p. 159-180, 2015.

UN - UNITED NATIONS. World Population Prospects 2019: Highlights. New York, N.Y.: Department of Economic and Social Affairs, Population Division, United Nations, 2019. Disponível em:

https://population.un.org/wpp/Publications/Files/WPP2019_Highlights.pdf. Acesso em: 27 de julho de 2020.

VAN VLIET, J. Direct and indirect loss of natural area from urban expansion. Nature Sustainability, v. 2, n. 8, p. 755-763, 2019.

XU, C., LIU, M.; ZHANG, C.; AN, S.; YU, W.; CHEN, J. M. The spatiotemporal dynamics of rapid urban growth in the Nanjing metropolitan region of China. Landscape Ecology, v. 22, p. 925-937, 2007.

XU, G.; ZHOU, Z.; JIAO, L.; ZHAO, R. Compact Urban Form and Expansion Pattern Slow Down the Decline in Urban Densities: A Global Perspective. Land Use Policy, v. 94, 2020.

YUNDA, J. G.; SLETTO, B. Densification, private sector-led development, and social polarization in the global south: Lessons from a century of zoning in Bogotá. Cities, v. 97, 102550, 2020.

ZAPATA-CAMPOS, M. J.; KAIN, J-H.; OLOKO, M.; STENBERG, J.; ZAPATA, P. Urban qualities and residents' strategies in compact global south cities: the case of Havana. Journal of Housing and the Built Environment, 2021. 
ZHOU, B.; RYBSKI, D.; KROPP, J. P. The role of city size and urban form in the surface urban heat island. Scientific Reports, v. 7, n. 1, 4791, 2017.

Recebido em: 07/08/2020

Aceito para publicação em: 15/10/2021 